\title{
The Microphthalmia-Associated Transcription Factor p.E318K Mutation Does Not Play a Major Role in Sporadic Renal Cell Tumors from Caucasian Patients
}

\author{
Christine G. Stoehr ${ }^{\mathrm{a}}$ Bernhard Walter ${ }^{\mathrm{b}}$ Stefan Denzinger ${ }^{\mathrm{c}}$ \\ Paola Ghiorzo $^{f}$ Richard A. Sturm ${ }^{g}$ Raoul Hinze ${ }^{d}$ Holger Moch $^{\text {h }}$ \\ Kerstin Junker ${ }^{\mathrm{e}}$ Arndt Hartmann ${ }^{\mathrm{a}}$ Robert Stoehr ${ }^{\mathrm{a}}$ \\ a Institute of Pathology and ${ }^{b}$ Department of Urology, University Hospital Erlangen, Friedrich Alexander University \\ Erlangen-Nuremberg, Erlangen, 'Department of Urology, University of Regensburg, Caritas St. Josef Medical \\ Center, Regensburg, 'Institute of Pathology, HELIOS Hospital Schwerin, Schwerin, and ' Department of Urology \\ and Pediatric Urology, Saarland University Medical Center, Homburg/Saar, Germany; ${ }^{f}$ Department of Internal and \\ Medical Specialties, University of Genoa, Genoa, Italy; ${ }^{9}$ Institute for Molecular Bioscience, University of Brisbane,

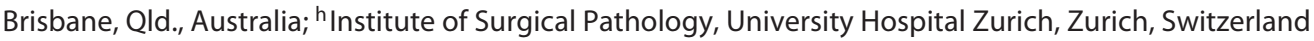

\section{Key Words}

Microphthalmia-associated transcription factor · Mutation · Renal cell carcinoma. Pyrosequencing

\footnotetext{
Abstract

Objective: The transcription factor MITF (microphthalmiaassociated transcription factor) is known to induce expression of hypoxia-inducible factor (HIF1-a), which is involved in renal carcinogenesis. The MITF p.E318K mutation leads to deficient SUMOylation of MITF, resulting in enhanced activation of its target genes. A case-control study on melanoma patients who coincidentally were affected by renal cell carcinoma (RCC) has revealed an elevated risk for mutation carriers to be affected by one or both of these malignancies, suggesting a possible role for MITF p.E318K in renal carcinogenesis. The same study described an MITF mutation frequency of $1.5 \%$ in a small cohort of sporadic RCC, but com-
}

prehensive data on sporadic renal cell tumors are missing. We therefore tested a large cohort of sporadic renal tumors for MITF p.E318K mutation status. Methods: Genomic DNA was extracted from 426 formalin-fixed, paraffin-embedded sporadic renal tumors that had been graded according to the 2004 WHO classification of renal tumors and staged according to the 2002 TNM classification. The tumor cohort was enriched with papillary and chromophobe RCC, and also contained benign oncocytomas. DNA was tested for MITF p.E318K by pyrosequencing. Results: Of 403 analyzable tumors, 402 renal tumors were wild-type ones, and only 1 case showed the MITF p.E318K mutation. This tumor was a clearcell RCC (pT3b NO MO G3 according to the TNM classification 2002). The affected patient was male, 61 years old, and had no known coexisting malignancies. Conclusion: The MITF p.E318K mutation does not appear to play a major role in sporadic RCC carcinogenesis, but is possibly restricted to a rare subpopulation of inherited $\mathrm{RCC}$.

(c) 2016 S. Karger AG, Basel

\section{KARGER}

E-Mail karger@karger.com www.karger.com/pat
(C) 2016 S. Karger AG, Basel

$1015-2008 / 16 / 0834-0165 \$ 39.50 / 0$
PD Dr. Dr. Robert Stoehr, PhD

Institute of Pathology, University Hospital Erlangen

Krankenhausstrasse 8-10

DE-91054 Erlangen (Germany)

E-Mail christine.stoehr@uk-erlangen.de 


\section{Introduction}

Cellular functions and intracellular communication are controlled and regulated both at the DNA and posttranslational levels. Posttranslational modifications (e.g. phosphorylation, ubiquitination, and acetylation) of proteins are essential for triggering signal cascades and for maintaining fundamental developmental processes. Dysregulation of posttranslational modification might lead to dramatic malfunction of the cell, and is known from most malignancies. However, as recently demonstrated, a deregulated posttranslational modification network may act as a therapeutic target (e.g. in pancreatic cancer), and is a major focus of ongoing studies in prostate cancer $[1,2]$.

Reversible covalent conjugation of SUMO (small ubiquitin-related modifier) is a posttranslational modification that can modulate the function (e.g. activity, cellular localization, and stability) of a large spectrum of proteins [3]. SUMOylation frequency of a target protein is increased by the presence of the consensus motif $\Psi \mathrm{KXE}$, but proteins without this motif might also be prone to this modification [4]. Of important functional relevance is a connection between the SUMOylation and ubiquitination networks, as SUMOylation can lead to ubiquitindependent degradation by the proteasome [5].

The MITF (microphthalmia-associated transcription factor) gene encodes for a basic-helix-loop-helix leucine zipper transcription factor and is part of the Myc supergene family. The MITF gene contains two SUMOylation sites that can regulate SUMOylation and transcriptional activity of the MITF protein [6].

Recently, a germline missense mutation (p.E318K) in the MITF gene was described, and a predisposition to familial and sporadic melanoma in carriers of this specific change was documented. The affected codon is located within a SUMOylation consensus motif, and the mutation interferes with MITF SUMOylation. In vitro studies revealed both enhanced binding of mutated MITF to the promoter of the hypoxia-inducible factor (HIF1- $\alpha$ ) gene, which is a target gene of the MITF transcription factor, and increased activity of the HIF1- $\alpha$ promoter caused by this binding $[7,8]$. Increased expression of HIF1- $\alpha$ is correlated with the development of clear-cell renal cell carcinomas (RCC), and overexpression of HIF1- $\alpha$ has been found in most clear-cell RCC cases analyzed to date [9]. Most interesting, a significantly increased frequency of RCC compared to normal controls was detected in melanoma patients with the p.E318K germline mutation in MITF $[7,10]$. These findings suggest MITF as a possible
Table 1. Patient and tumor characteristics $(n=426)$

$\begin{array}{lr}\text { Gender, } \mathrm{n} & \\ \text { Male } & 217 \\ \text { Female } & 131 \\ \text { Unknown } & 78 \\ \text { Age, years } & \\ \text { Range } & 19-91 \\ \text { Median } & 65 \\ \text { Mean } & 63.04 \\ \text { Tumor type, n } & \\ \text { Clear-cell RCC } & 175 \\ \text { Papillary RCC } & 77 \\ \text { Chromophobe RCC } & 97 \\ \text { Renal oncocytoma } & 58 \\ \text { Others } & 19 \\ \text { 2002 TNM classification, } \mathrm{n} & \\ \text { pT1a } & 129 \\ \text { pT1b } & 80 \\ \text { pT2 } & 58 \\ \text { pT3a } & 41 \\ \text { pT3b } & 31 \\ \text { Unknown } & 29 \\ \text { 2002 TNM stage, n } & \\ \text { Stage I } & 160 \\ \text { Stage II } & 32 \\ \text { Stage III } & 47 \\ \text { Stage IV } & 21 \\ \text { Unknown } & 108\end{array}$

connection point between melanoma and RCC. In addition, mutation analysis of a small cohort of sporadic RCC cases showed a MITF p.E318K mutation frequency of $1.5 \%$ [7]. Currently, the role of the MITF mutation in RCC development remains unclear, as comprehensive mutation data from sporadic RCC cases are missing. Therefore, the aim of our study was to screen a large cohort of Caucasian sporadic renal tumor cases for the MITF p.E318K mutation.

\section{Materials and Methods}

Patients and Tissue Samples

Overall, 426 formalin-fixed, paraffin-embedded archival sporadic renal tumors were used for the study. The cases were classified according to the $2004 \mathrm{WHO}$ classification of renal tumors and staged according to the 2002 TNM classification [11, 12]. Characteristics of the study cohort are shown in table 1. Prior institutional review board approval (University Hospital Erlangen, Germany) was obtained for the study. 
Tissue Microdissection and DNA Isolation

DNA was extracted from renal tumor samples from serial sections after manual microdissection as described previously [13]. In brief, $5-\mu \mathrm{m}$-thick serial sections of the tumor tissue were dewaxed and stained with $0.1 \%$ methylene blue for $15 \mathrm{~s}$. Using an inverted microscope, the tumor tissue (identified through matching with a marked hematoxylin and eosin-stained section reviewed by an experienced surgical pathologist) was scraped off with a sterile needle to obtain a purity of the cells of at least $85 \%$. Isolation of genomic DNA of the microdissected tumor tissue was performed using the High Pure PCR Template Preparation Kit (Roche, Mannheim, Germany) according to the manufacturer's instructions.

\section{Sequence Analysis of Codon 318 of MITF}

For mutation analysis, the hot spot region of the MITF gene containing codon 318 was amplified using the multiplex PCR-kit according to manufacturer's instructions (Qiagen, Hilden, Germany) and the following primers: forward: $5^{\prime}$-TTATTCCATCCACGGGTCTC-3', and reverse: $5^{\prime}$-biotin GAGGTCTTGGCTGCAGTTCT- $3^{\prime}$. The cycling conditions were as follows: a single cycle of denaturation at $94^{\circ} \mathrm{C}$ for $5 \mathrm{~min}, 45$ cycles at $94^{\circ} \mathrm{C}$ for 1 $\min , 58.3^{\circ} \mathrm{C}$ for $1 \mathrm{~min}$, and $72^{\circ} \mathrm{C}$ for $1 \mathrm{~min}$, and a final 10 -min extension at $72^{\circ} \mathrm{C}$. For pyrosequencing (PyroMark Q24; Qiagen) single-stranded DNA was prepared from $25 \mathrm{ml}$ of biotinylated PCR product with streptavidin-coated sepharose and $0.5 \mathrm{mM}$ of the sequencing primer $5^{\prime}$-AATCGGATCATCAAGC-3' using the PSQ Vacuum Prep Tool (Qiagen). Pyrosequencing assay setup was selected in 'Sequence to Analyze' with the sequence AAG/A AAC CCG TT. The following dispensation order was used: GAA GAC GT.

\section{Results}

Sequencing data were available from 403/426 (94.6\%) cases. In 23 cases, no PCR products were obtained due to strong fragmentation of the DNA after formalin fixation. Of the 403 analyzable cases, 402 (99.8\%) showed wildtype MITF p.E318. Only 1 (0.2\%) case showed the MITF p.E318K mutation (fig. 1). This case was a clear-cell RCC (pT3b N0 M0 G3 according to the TNM classification 2002). The affected patient was male, 61 years old, and had no known coexisting malignancies.

\section{Discussion}

In this study we analyzed the p.E318K mutation of MITF in a large cohort of sporadic renal cell tumors. Only one of the cases investigated showed the mutation known as a germline alteration from patients with familial melanoma and/or RCC. The resulting allele frequency of the mutation in our cohort was $0.12 \%$. The low frequency detected might hint to technical problems or contaminated material, but positive and negative controls showed the expected results. Moreover, this mutation frequency was comparable to those of the general populations of France (frequency $=0.3 \%$ ), Australia (frequency $=0.72 \%)$, Poland $(0.09 \%)$, and the UK (frequen$c y=0.85 \%)[8,14,15]$. Furthermore, Guo et al. [16] performed exome sequencing on 10 clear-cell RCC and screened $>1,000$ genes (including MITF) in an additional 88 clear-cell RCC cases, but could not detect an MITF mutation. Furthermore, the TCGA Research Network published an extensive molecular profiling of 417 clearcell RCC samples. Overall, MITF alterations were reported in $2.6 \%$ of the cases with $9 / 11$ mutated tumors showing deep deletions and only $2 / 11$ mutated tumors displaying point mutations (p.T110M, p.G165D). The p.E318K mutation could not be detected at all [17]. Through cBioPortal $[18,19]$, provisional sequencing data from an additional 161 papillary RCC cases analyzed by the TCGA Research Network are available. In this cohort, $3 / 161(2.6 \%)$ cases showed truncating (p. K118*, p.K198fs) or missense (p.A205V) mutations within the MITF gene. Again, the p.E318K mutation allele was not found. Thus, combining all available data, the overall MITF mutation frequency is approximately $1.4 \%$ (15/1,079 cases with mutation).

Altogether, these data support our results on MITF p.E318K frequency in sporadic RCC and therefore argue for their validity. In conclusion, the MITF p.E318K mutation only plays a minor role in the development of sporadic RCC.

Despite the rarity of MITF mutations, they might trigger RCC development in specific cases, as mutated MITF displays enhanced binding to the HIF1- $\alpha$ promoter and has been shown to increase HIF1- $\alpha$ promoter activity. Moreover, MITF also acts as a transcription factor and is able to directly control MET transcription [20]. Activating mutations in the MET proto-oncogene are especially frequent in papillary type 1 RCC (about 15\%) [21]. These mutations lead to activation of several pathways resulting in, for example, tumor cell proliferation, invasion, and angiogenesis. Mutations in MITF interrupting its controlled degradation might constantly increase MET transcription and result in similar effects as mutational MET activation. It is conceivable that this effect, in combination with additional harmful events, makes a cell prone to malignant transformation. This is supported by the recent description of an actin gamma 1 (ACTG1)-MITF fusion in a case of papillary RCC [22]. In vitro studies of this fusion protein revealed an induction of, for example, HIF1- $\alpha$ and MET transcription in HEK293T cells, and an 
Fig. 1. Representative examples for pyrosequencing analysis (pyrogram) of codon 318 (5'-GAA-3') of the MITF gene. a RCC showing a wild-type sequence. b Positive control for the MITF p.E318K (5'-GAA-3' $\rightarrow 5^{\prime}$-AAA- $3^{\prime}$ ) mutation from a melanoma case with the germline mutation. The downward-pointing arrow indicates the reduction of the wild-type ' $G$ ' signal and the increase in the mutant ' $A$ ' signal. The ' $G$ '-to-'A' mutation led to a stretch of $5 \times$ ' $A$ ' in a row interrupted by the ' $G$ ' signal (downward-pointing arrow) from the wild-type background. c Clear-cell RCC with the MITF p.E318K mutation. The pyrogram is identical to that of the positive control. d Negative control $\left(\mathrm{H}_{2} \mathrm{O}\right)$.

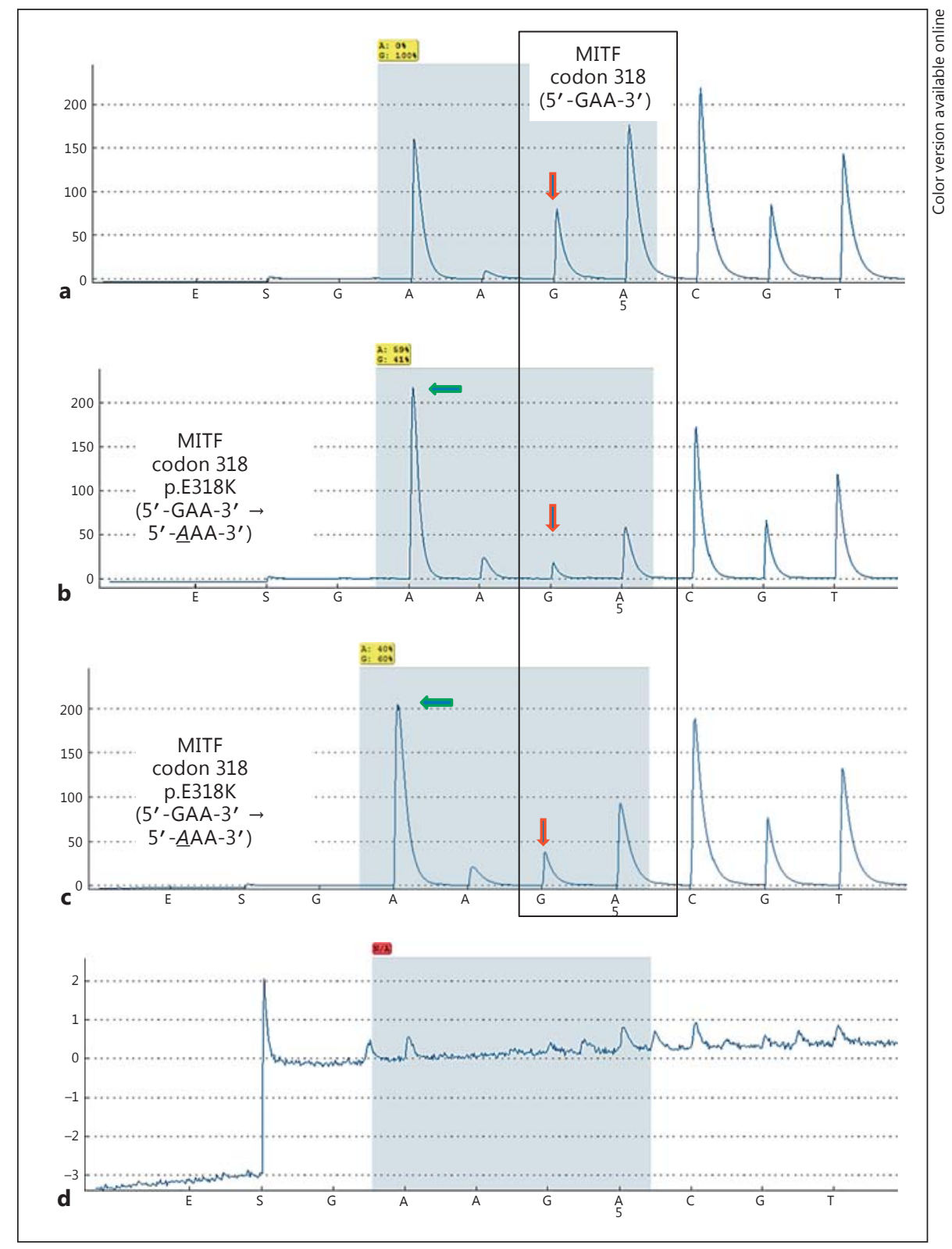

increased colony-forming ability in NIH3T3 cells. These data gave the first evidence for a similar tumorigenic potential of MITF fusion proteins as is attributed to TFE3 fusions.

In summary, the MITF p.E318K mutation does not seem to play a major role in sporadic RCC development in Caucasians, but is possibly restricted to a rare subpopulation of inherited RCC. Nonetheless, in general, MITF alterations might contribute to the development of sporadic RCC as they affect targets already known to be involved in RCC pathobiology.

\section{Acknowledgement}

The authors thank Verena Popp, Karina Kalb, Claudia Knoll, and Nina Oks for excellent technical assistance.

\section{Disclosure Statement}

The authors have no conflict of interest. 


\section{References}

1 Chen Z, Lu W: Roles of ubiquitination and SUMOylation on prostate cancer: mechanisms and clinical implications. Int J Mol Sci 2015;16:4560-4580.

2 Damaskos C, Karatzas T, Nikolidakis L, Kostakis ID, Karamaroudis S, Boutsikos G, et al: Histone deacetylase (HDAC) inhibitors: current evidence for therapeutic activities in pancreatic cancer. Anticancer Res 2015;35: 3129-3135.

3 Sriramachandran AM, Dohmen RJ: SUMOtargeted ubiquitin ligases. Biochim Biophys Acta 2014;1843:75-85.

4 Yang XJ, Chiang CM: SUMOylation in gene regulation, human disease, and therapeutic action. F1000Prime Rep 2013;5:45.

5 Miteva M, Keusekotten K, Hofmann K, Praefcke GJ, Dohmen RJ: SUMOylation as a signal for polyubiquitylation and proteasomal degradation. Subcell Biochem 2010;54:195-214.

6 Paillerets BB, Lesueur F, Bertolotto C: A germline oncogenic MITF mutation and tumor susceptibility. Eur J Cell Biol 2014;93: 71-75.

7 Bertolotto C, Lesueur F, Giuliano S, Strub T, de Lichy M, Bille K, et al: A SUMOylationdefective MITF germline mutation predisposes to melanoma and renal carcinoma. $\mathrm{Na}$ ture 2011;480:94-98.

8 Yokoyama S, Woods SL, Boyle GM, Aoude LG, MacGregor S, Zismann V, et al: A novel recurrent mutation in MITF predisposes to familial and sporadic melanoma. Nature 2011;480:99-103.
9 Gudas LJ, Fu L, Minton DR, Mongan NP, Nanus DM: The role of HIF1a in renal cell carcinoma tumorigenesis. J Mol Med 2014;92: 825-836.

10 Ghiorzo P, Pastorino L, Queirolo P, Bruno W, Tibiletti MG, Nasti S: Prevalence of the E318K MITF germline mutation in Italian melanoma patients: associations with histological subtypes and family cancer history. Pigment Cell Melanoma Res 2013;26:259-262.

11 Eble JN SG, Epstein JI, et al: Tumours of the Urinary System and Male Genital Organs. Lyon, IARC Press, 2004.

12 Sobin LH, Wittekind C (eds): TNM Classification of Malignant Tumors, ed 6. New York, John Wiley \& Sons, 2002.

13 Stoehr R, Taubert H, Zinnall U, Giedl J, Gaisa NT, Burger M, et al: Frequency of TERT promoter mutations in prostate cancer. Pathobiology 2015;82:53-57.

14 Sturm RA, Fox C, McClenahan P, Jagirdar K, Ibarrola-Villava M, Banan P, et al: Phenotypic characterization of nevus and tumor patterns in MITF E318K mutation carrier melanoma patients. J Invest Dermatol 2014;134: 141-149.

15 Gromowski T, Masojc B, Scott RJ, Cybulski C, Gorski B, Kluzniak W, et al: Prevalence of the E318K and V320I MITF germline mutations in Polish cancer patients and multiorgan cancer risk-a population-based study. Cancer Genet 2014;207:128-132.
16 Guo G, Gui Y, Gao S, Tang A, Hu X, Huang $\mathrm{Y}$, et al: Frequent mutations of genes encoding ubiquitin-mediated proteolysis pathway components in clear cell renal cell carcinoma. Nat Genet 2011;44:17-19.

17 Cancer Genome Atlas Research Network: Comprehensive molecular characterization of clear cell renal cell carcinoma. Nature 2013; 499:43-49.

18 Cerami E, Gao J, Dogrusoz U, Gross BE, Sumer SO, Aksoy BA, et al: The cBio cancer genomics portal: an open platform for exploring multidimensional cancer genomics data. Cancer Discov 2012;2:401-404.

19 Gao J, Aksoy BA, Dogrusoz U, Dresdner G, Gross B, Sumer SO, et al: Integrative analysis of complex cancer genomics and clinical profiles using the cBioPortal. Sci Signal 2013; 6:pl1.

20 Beuret L, Flori E, Denoyelle C, Bille K, Busca $\mathrm{R}$, Picardo $\mathrm{M}$, et al: Up-regulation of MET expression by alpha-melanocyte-stimulating hormone and MITF allows hepatocyte growth factor to protect melanocytes and melanoma cells from apoptosis. J Biol Chem 2007;282: 14140-14147.

21 Massari F, Ciccarese C, Santoni M, Brunelli M, Piva F, Modena A, et al: Metabolic alterations in renal cell carcinoma. Cancer Treat Rev 2015;41:767-776.

22 Durinck S, Stawiski EW, Pavia-Jimenez A, Modrusan Z, Kapur P, Jaiswal BS, et al: Spectrum of diverse genomic alterations define non-clear cell renal carcinoma subtypes. Nat Genet 2015;47:13-21. 